\title{
Assessment of Penetration Depth and Microleakage of Different Pit and Fissure Sealants Using Dye Penetration Method: An In Vitro Study
}

\author{
Arti Dixit ${ }^{1}$, Naman Awasthi ${ }^{2}$, Shruti Jha ${ }^{3}$, Suprasidh Suprakasam ${ }^{4}$, Narendra V Penumatsa ${ }^{5}$, Aravind A Vijayan ${ }^{6}$
}

\begin{abstract}
Aim and objective: The aim of this study was to evaluate the depth of penetration as well as the microleakage of three different pit and fissure sealant materials employing the dye penetration method.

Materials and methods: Sixty healthy human mandibular premolar teeth without dental caries that were extracted for orthodontic treatment constituted the study samples. These 60 premolar samples were subjected to an equal division (20 in every group) into three groups. Group I: self-adhering flowable composite, group II: flowable nanocomposites, group III: classical pit and fissure sealants. Every sample tooth underwent thermocycling amid $4^{\circ} \mathrm{C} \pm 2^{\circ} \mathrm{C}$ and $60^{\circ} \mathrm{C} \pm 2^{\circ} \mathrm{C}$ for 1,000 cycles. The samples were placed in $1 \%$ methylene blue solution for 24 hours to permit diffusion of the dye into probable gaps in between the restoration and the tooth. The teeth were sectioned and evaluated below a stereomicroscope at $10 \times$ magnification with image analysis software.

Results: Flowable nanocomposites $(3.69 \pm 0.10)$ exhibited a slightly greater mean depth of penetration as compared to classical pit and fissure sealants $(3.58 \pm 0.16)$ and self-adhering flowable composites $(3.51 \pm 0.13)$ in that order. This difference between the three sealants was not significant statistical. Amid the three sealant study groups, the lowest mean marginal microleakage was exhibited by the flowable nanocomposites $(1.06 \pm 0.03)$, followed by self-adhering flowable composites $(1.98 \pm 0.06)$, and classical pit and fissure sealants $(2.74 \pm 0.11)$. Analysis of variance revealed statistically significant differences among the three sealants that were studied.

Conclusion: This study concludes that flowable nanocomposites depicted enhanced penetration and reduced marginal leakage as compared to the self-adhering flowable composites and classical pit and fissure sealants.

Clinical significance: An efficient approach to preventing dental caries on the occlusal surfaces of teeth is the use of pit and fissure sealants. The efficiency of sealants chiefly depends on the morphological characteristics of the fissures and properties of dental materials used.

Keywords: Fissure morphology, Microleakage, Penetration, Sealants.

The Journal of Contemporary Dental Practice (2021): 10.5005/jp-journals-10024-3132
\end{abstract}

\section{INTRODUCTION}

Although dental caries are amid the frequent microbial diseases affecting mankind, their occurrence in children, as well as adolescents, has reduced in recent years, owing to several preventive steps that were sought in developing countries. Despite the benefit of caries preventing methods to smooth surfaces of teeth particularly the proximal surface, the high rate of dental caries affecting the occlusal surface of teeth still remains problematic. The chief reason for this setback is the complicated morphology of the pits and fissures present on the palatal, occlusal and buccal surface of the molars, which are vulnerable sites for the development of dental caries. ${ }^{1}$

Techniques including sealing of the predisposed fissures using zinc phosphate cement, mechanically obliterating fissures, silver nitrate chemical management, and preventive odontology are among the various preventive methods that have been adopted to battle this issue. ${ }^{2}$ Pit and fissure sealants are materials inserted in the pits and fissures on the occlusal surface of teeth prone to dental caries resulting in a layer of protection with a micromechanical bond that eliminates the entry of dental caries causing bacteria from their nutrition resources as described by Simonsen. ${ }^{3}$

The two variants of the commercially available pit and fissure sealants these days are either glass-ionomer or resin-based. Depending on the manner of polymerization or their composition, the sealants which are resin-based are classified into various
${ }^{1}$ Department of Public Health Dentistry, Vaidik Dental College and Research Centre, Daman, Daman and Diu, India

${ }^{2}$ Department of Dentistry, Government Medical College, Shahdol, Madhya Pradesh, India

${ }^{3}$ Department of Pedodontics, Post Graduate Institute of Dental Sciences, Rohtak, Haryana, India

${ }^{4}$ Department of Pediatric and Preventive Dentistry, Sri Sankara Dental College, Thiruvananthapuram, Kerala, India

${ }^{5}$ Department of Preventive Dental Sciences, College of Dentistry, Prince Sattam Bin Abdul Aziz University, Al-Kharj, Saudi Arabia

${ }^{6}$ Department of Dentistry, Mount Zion Medical College, Adoor, Kerala, India

Corresponding Author: Arti Dixit, Department of Public Health Dentistry, Vaidik Dental College and Research Centre, Daman, Daman and Diu, India, Phone: +91 9712042464, e-mail: dr.dixitarti@gmail.com How to cite this article: Dixit A, Awasthi N, Jha S, et al. Assessment of Penetration Depth and Microleakage of Different Pit and Fissure Sealants Using Dye Penetration Method: An In Vitro Study. J Contemp Dent Pract 2021;22(8):890-893.

Source of support: Nil

Conflict of interest: None

generations. Depending on the mechanism of curing, these sealants are categorized as chemically cured, light-activated, fluoride-

(0) The Author(s). 2021 Open Access This article is distributed under the terms of the Creative Commons Attribution 4.0 International License (https://creativecommons. org/licenses/by-nc/4.0/), which permits unrestricted use, distribution, and non-commercial reproduction in any medium, provided you give appropriate credit to the original author(s) and the source, provide a link to the Creative Commons license, and indicate if changes were made. The Creative Commons Public Domain Dedication waiver (http://creativecommons.org/publicdomain/zero/1.0/) applies to the data made available in this article, unless otherwise stated. 
discharging, or self-curing. Filled and unfilled varieties of resinbased sealants are another classification based on the existence or lack of fillers. Microscopic glass beads, particles of quartz, and composite resin fillers constitute filled types of sealants. ${ }^{4}$

The clinical efficiency of these sealants is dependent on their retention which is in turn related to the pit and fissure morphological characteristics, provision of appropriate isolation, traits of the materials, and the technique of application. The retention of fissure sealants may be enhanced by cleansing the occlusal surface before placing the sealant with prophylactic pumice, air abrasion, and polishing as well by mechanically preparing the fissures which are referred to as the invasive technique. ${ }^{5}$ An additional significant factor for a successful sealant is the marginal integrity that can be estimated by assessment of the microleakage. The seepage of bacteria and oral fluids in the space amid the restoration and tooth structure is defined as microleakage. Microleakage can cause progress of dental caries beneath the restoration in the absence of appropriate sealing. ${ }^{6}$

Thus, the current study was performed to evaluate the depth of penetration as well as the microleakage of three different pit and fissure sealant materials employing the dye penetration method.

\section{Materials and Methods}

\section{Sample Selection}

The current in vitro study was performed in the department of public health dentistry, Vaidik Dental College and Research Centre, Daman, India. Sixty healthy human mandibular premolar teeth without dental caries that were extracted for orthodontic treatment constituted the study samples and were disinfected by 48 hours storage in $0.5 \%$ Chloramine-T solution (Merck, Darmstadt, Germany). Each tooth was assessed clinically employing standard lighting and an explorer to be declared free from dental caries. Every sample was subjected to cleansing to eliminate calculus and soft tissue debris with a hand scaler. About $0.9 \% \mathrm{NaCl}$ consisting of $0.02 \%$ sodium azide was used to store the cleaned teeth at $4^{\circ} \mathrm{C}$ until they were utilized for the study. The premolars were organized for surface cleaning prophylaxis with pumice and Klint Paste ${ }^{\circledast}$ (Voco). These 60 premolar samples were subjected to an equal division (20 in every group) into three groups. The sealant application to the pits and fissures was performed in concordance with the recommendations of the manufacturer.

\section{Group I: Self-adhering Flowable Composite}

Dyad flow (Dyad flow; Kerr, Sybron dental specialties, USA) application was directly done to the sample teeth using the manufacturer-provided syringe. Surplus material was taken off with a brush given by the manufacturer. The sealant was then subjected to UV light curing for 20 seconds.

\section{Group II: Flowable Nanocomposite}

In each sample, the enamel of the occlusal surface was subjected to $37 \%$ phosphoric acid etching for 30 seconds. Following etching, the surface was subject to rinsing and drying with air. The Tetric N-Flow (Tetric N-Flow; Ivoclar Vivadent AG) sealant was applied on to the fissures in accordance with the guidelines of the manufacturer. In order to avoid air-inclusion and voids, tip of a periodontal probe (API) was passed through the fissure tenderly. A light-curing unit was then employed on the occlusal surface to achieve polymerization. A bonding agent application to the fissures was done with a microbrush and subjected to polymerization for 20 seconds before applying the sealant.

\section{Group III: Classical Pit and Fissure Sealant}

In each sample, the enamel of the occlusal surface was subjected to $37 \%$ phosphoric acid etching for 30 seconds. Following etching, the surface was subjected to rinsing and drying with air. The Helioseal F (Helioseal F; Ivoclar Vivadent AG, Schaan, Liechtenstein) sealant was applied on to the fissures in accordance with the guidelines of the manufacturer. In order to avoid air-inclusion and voids, tip of a periodontal probe (API) was passed through the fissure tenderly. A light-curing unit was then employed on the occlusal surface to achieve polymerization for 20 seconds.

\section{Thermocycling and Dye Penetration Procedure}

Every sample tooth underwent thermocycling amid $4^{\circ} \mathrm{C} \pm 2^{\circ} \mathrm{C}$ and $60^{\circ} \mathrm{C} \pm 2^{\circ} \mathrm{C}$ for 1,000 cycles. The dwell span in every bath and the time gap at room temperature involving baths was 60 seconds. Following thermocycling, the tooth surfaces, excluding the restorations and $1.5 \mathrm{~mm}$ beyond the margins, were subjected to coating with dual layer of nail varnish. The samples that had been coated were placed in $1 \%$ methylene blue solution for 24 hours to permit diffusion of the dye into probable gaps in between the restoration and the tooth. After exposure to the dye, distilled water was used to wash and rinse the samples.

\section{Assessment of Microleakage}

The samples were cleansed with water to get rid of surplus dye and were then divided buccolingually in the course of the sealant by means of a high-speed straight handpiece, diamond disk, and water mist. These sectioned teeth were evaluated below a stereomicroscope at $10 \times$ magnification with image analysis software (SigmaScan, SPSS; Jandel Scientific, San Rafael, California, USA). Scores were allocated to every sample in agreement with the sealant penetration depth, and microleakage was expressed in millimeters and measured by two examiners.

Theodoridou-Pahini et al. ${ }^{7}$ microleakage scoring criteria were employed to evaluate the amount of dye penetration which is as under.

Score $0=$ Absence of dye penetration

Score $1=$ Penetration of the dye down the buccal or lingual wall Score $2=$ Penetration of the dye down the buccal or lingual wall Score $3=$ Penetration of the dye beneath the sealant and down the lingual or buccal wall

Score 4 = Penetration of the dye all about the sealant

The sealant penetration depth was assessed using MLC Fracasso ${ }^{8}$ criteria as follows:

Score $0=$ no penetration in shallow, medium, and deep fissures

Score $1=$ shallow fissure with partial penetration

Score 2 = shallow fissure with total penetration and medium fissure with partial penetration

Score 3 = medium fissure with total penetration and deep fissure with partial penetration

Score 4 = deep fissure with total penetration

\section{Statistical Analysis}

SPSS 20.0 was utilized for the data management and analysis. One-way analysis of variance (ANOVA) test was employed for penetration depth and microleakage comparison. Tukey's post hoc examination was employed for various analogies. Statistical significance was ascertained with a $p$-value less than 0.05 . 


\section{Results}

Table 1 depicts the mean depth of sealant penetration into the pits and fissures. Flowable nanocomposites $(3.69 \pm 0.10)$ exhibited a slightly greater mean depth of penetration as compared to classical pit and fissure sealants $(3.58 \pm 0.16)$ and self-adhering flowable composites $(3.51 \pm 0.13)$ in that order. This difference between the three sealants was not significant statistically.

Table 2 shows the comparative assessment of the mean marginal microleakage among the three sealant study groups. The lowest mean marginal microleakage was exhibited by the flowable nanocomposites $(1.06 \pm 0.03)$, followed by self-adhering flowable composites $(1.98 \pm 0.06)$ and classical pit and fissure sealants $(2.74 \pm 0.11)$. ANOVA revealed statistically significant differences among the three sealants that were studied.

Table 3 denotes various comparisons of marginal microleakage among the three sealant groups that were studied using Turkey HSD. The difference between group II and group III was statistically significant while group I vs group II, as well as group I vs group III, depicted no statistically significant differences.

The inference of the present study indicates that the flowable nanocomposite group showed better penetration and less marginal leakage than self-adhering flowable composite group and classical pit and fissure sealant group.

Table 1: Assessment of mean penetration depth of the sealant into pit and fissures

\begin{tabular}{lllll}
\hline $\begin{array}{l}\text { Pit and fissure sealant } \\
\text { groups }\end{array}$ & Mean \pm SD & Fvalue & pvalue & Significance \\
\hline $\begin{array}{l}\text { Group I: Self-adhering } \\
\text { flowable composite }\end{array}$ & $3.51 \pm 0.13$ & & & \\
$\begin{array}{l}\text { Group II: Flowable } \\
\text { nanocomposite }\end{array}$ & $3.69 \pm 0.10$ & 24.182 & 0.617 & NS \\
$\begin{array}{l}\text { Group III: Classical pit } \\
\text { and fissure sealant }\end{array}$ & $3.58 \pm 0.16$ & & & \\
\hline$p>0.05 ;$ NS, not significant & & & & \\
\hline
\end{tabular}

Table 2: Comparison of mean marginal microleakage between the three different study groups

\begin{tabular}{lllll}
\hline $\begin{array}{l}\text { Pit and fissure sealant } \\
\text { groups }\end{array}$ & Mean \pm SD & Fvalue & pvalue & Significance \\
\hline $\begin{array}{l}\text { Group I: Self- } \\
\text { adhering flowable } \\
\text { composite }\end{array}$ & $1.98 \pm 0.06$ & & & \\
$\begin{array}{l}\text { Group II: Flowable } \\
\text { nanocomposite }\end{array}$ & $1.06 \pm 0.03$ & 23.642 & 0.001 & HS \\
$\begin{array}{l}\text { Group III: Classical pit } \\
\text { and fissure sealant }\end{array}$ & $2.74 \pm 0.11$ & & & \\
\hline$p<0.05 ; \mathrm{HS}$, highly significant & & & & \\
\end{tabular}

Table 3: Multiple comparisons of marginal microleakage between the three different study groups using Tukey HSD

\begin{tabular}{llcl}
\hline Group & Compared with & Mean difference (I-J) & Sig. \\
\hline \multirow{2}{*}{ Group I } & Group II & 0.92 & 0.071 \\
& Group III & -0.76 & 0.062 \\
\multirow{2}{*}{ Group II } & Group I & -0.92 & 0.071 \\
& Group III & -1.68 & $\mathbf{0 . 0 0 1}^{*}$ \\
\multirow{2}{*}{ Group III } & Group I & 0.76 & 0.062 \\
& Group II & 1.68 & $\mathbf{0 . 0 0 1}^{*}$ \\
\hline
\end{tabular}

*Significant, $p<0.05$

\section{Discussion}

Irrespective of the socioeconomic status and age, dental caries is a highly prevalent pathosis that affects almost every geographical region. Over the last decade, dental caries in the deciduous teeth that were not treated were categorized as the 10th most prevalent disease in the world while dental caries in the permanent teeth that were not treated remained the most prevalent disease. Although a multitude of advances in preventive strategies and dental material techniques are eminent, both the incidence and prevalence of dental caries in several countries have consistently stayed high. Dental decay is considered to be a "noncommunicable" and "behavioral" problem affecting the teeth. Dental caries initiation requires a net hard tissue demineralization to occur. This is a result of $\mathrm{pH}$ discrepancies and cariogenic bacteria that flourish in the acidic environment especially in the company of sugars that are fermentable. ${ }^{8}$

One amid the highly successful method of prevention of dental caries is pit and fissure sealant materials. Fissure sealants provide swift protection of occlusal surfaces of teeth by physically blocking the fissures which are prone to decay, particularly in small children. The benefits obtained from these agents depend on their physical properties and are directly related to the retention rate they offer in the oral cavity. Sealants must be capable of staying intact and having a firm adherence to tooth structure in order to avoid microleakage. Numerous factors affect the tooth and sealant interface integrity. These include fissure anatomy, the oral environment, chemical and mechanical properties of the materials used, and the forces of mastication. ${ }^{9}$

The sealant materials that have been developed off late are highly enhanced versions of those used before when considering the depth of penetration and their viscosity. The traditional composites were not regarded as efficient pit and fissure sealants owing to their greater viscosity. In contrast, novel composites like flowable composites and nanocomposites have lesser viscosity thereby offering an acceptable flow. This study thus had an aim to assess the efficiency of the recent new composites when employed as pit and fissure sealants. Stritikus et al. ${ }^{10}$ and Burrow et al. ${ }^{11}$ criteria were used to select the study samples in the current study. Healthy premolar teeth, not affected by caries were selected as these teeth present appropriate morphological traits of occlusal fissures. Additionally, they are frequently extracted for causes apart from dental caries leaving their occlusal fissure architecture preserved.

In this study, flowable nanocomposites exhibited slightly greater mean depth of penetration as compared to classical pit and fissure sealants and self-adhering flowable composites in that order. This difference amid the three sealants was not significant statistically ( $p>0.05)$ when considering the penetration depth. These results are in agreement with Autio-Gold ${ }^{12}$ and Duangthip et al. ${ }^{13}$ which can be attributed to polymerization shrinkage of the supplies that are related to characteristics like the quality of adhesion, viscoelasticity, and their curing procedures.

In the current study, the lowest mean marginal microleakage was exhibited by the flowable nanocomposites, followed by self-adhering flowable composites and classical pit and fissure sealants. This study revealed that all study groups showed a certain degree of penetration of the dye which is in harmony with the study of Theodoridou-Pahini et al. ${ }^{7}$ and do Rego and de Araujo ${ }^{14}$ who acknowledged that microleakage may be anticipated in all materials used for restorative purposes. This can also result from the lower coefficient of thermal expansion of the teeth when compared to the 
much higher coefficient of thermal expansion of fissure sealants. In this research, classical sealants showed higher microleakage as compared to flowable and self-adhering composites. This is in agreement with the study by Francescut et al. ${ }^{15}$ who did the depth of penetration and microleakage evaluation among flowable composites and conventional sealants.

Flowable composite sealants are basically the resin type of composites with less filler constitution and a higher portion of diluent monomers in their preparation. Owing to this, they present greater flow ability, better adaptation to the tooth surface, ease of insertion, and more elasticity. ${ }^{16} \mathrm{~A}$ combination of the composite resin technology as well as adhesives is the Dyad flow self-adhering flowable composite. This is achieved by the addition of the bonding agent that is the acidic adhesive monomer within the self-adhering flowable composite. The Dyad flow relies on the micromechanical as well as chemical relation amid the tooth surface or any other matter and the material. ${ }^{17}$

This study also has certain limitations. Every pit and fissure sealant may act uniquely as it depends on the environment. Numerous factors like the morphology of the fissures and their preparation, manner of applying the adhesive, etched enamel with acid as well as presence or absence of fissure surface contamination. Hence, it is recommended that alike research including contamination with saliva be executed. Also more in vivo studies utilizing different flowable restoration supplies and other methodologies of preparation must be performed for more clarity on the clinical involvement of every variable. Keeping this in mind, other factors like longer adaptation and the shear bond strength of the sealant materials must be taken into consideration.

\section{Conclusion}

Despite the limitations of this study, it may be concluded that flowable nanocomposites depicted enhanced penetration and reduced marginal leakage as compared to the self-adhering flowable composites and classical pit and fissure sealants.

\section{References}

1. Ratnaditya A, Kumar MGM, Avula SS, Jogendra MZ, Kandregula CR, Chowdhary Kopuri RK. Clinical evaluation of retention in hydrophobic and hydrophillic pit and fissure sealants: a two year follow-up study. J Young Pharm 2015;7(3):171-179. DOI: 10.5530/ jyp.2015.3.6.

2. Lele GS, Bhide PC. Evaluation of dyad flow as a pit and fissure sealant: an in-vitro pilot study. Int J Oral Health Med Res 2016;2(6):62-66. Available from: http://www.ijohmr.com/upload/Evaluation\%20 of $\% 20$ Dyad $\% 20$ Flow $\% 20$ as $\% 20$ a $\% 20$ Pit $\% 20$ and $\% 20$ Fissure $\% 20$ Sealant-\%20An\%20In-Vitro\%20Pilot\%20Study.pdf
3. Simonsen RJ. Chapter 2: pit and fissure sealants. In: Clinical applications of the acid etch technique. 1st ed. Chicago, IL: Quintessence Publishing Co, Inc; 1978. p. 19-42.

4. Babu G, Mallikarjun S, Wilson B, et al. Pit and fissure sealants in pediatric dentistry. SRM J Res Dent Sci 2014;5(4):253-257. DOI: 10.4103/0976-433X.145131.

5. Salama FS, Al-Hammad NS. Marginal seal of sealant and compomer materials with and without enameloplasty. Int J Pediatr Dent 2002;20:28-32. https://pubmed.ncbi.nlm.nih.gov/11853247/

6. Singla A, Garg S, Jindal SK, et al. In vitro evaluation of marginal leakage using invasive and noninvasive technique of light cure glass ionomer and flowable polyacid modified composite resin used as pit and fissure sealant. Indian J Dent Res 2011;22(2):205-209. DOI: 10.4103/0970-9290.84286.

7. Theodoridou-Pahini S, Tolidis K, Papadogiannis Y. Degree of microleakage of some pit and fissure sealants: an in vitro study. Int J Paediatr Dent 1996;6(3):173-176. DOI: 10.1111/j.1365-263x.1996. tb00237.x.

8. Fracasso MLC, Rios D, Machado MAAM, et al. Evaluation of marginal microleakage and depth of penetration of glass ionomer cements used as occlusal sealants. J Appl Oral Sci 2005;13(3):269-274. DOI: 10.1590/S1678-77572005000300013.

9. Kassebaum NJ, Bernabé E, Dahiya $M$, et al. Global burden of untreated caries: a systematic review and metaregression. J Dent Res 2015;94(5):650-658. DOI: 10.1177/0022034515573272.

10. Stritikus J, Owens B. An in vitro study of microleakage of occlusal composite restorations polymerized by a conventional curing light and a PAC curing light. J Clin Pediatr Dent 2000;24(3):221-227. Available from: https://pubmed.ncbi.nlm.nih.gov/11314147/

11. Burrow MF, Burrow JF, Makinson OF. Pits and fissures; Relative space contribution in fissures from sealants, prophylaxis pastes and organic remnants. Aust Dent J 2003;48(3):175-179. DOI: 10.1111/j.18347819.2003.tb00028.x.

12. Autio-Gold JT. Clinical evaluation of a medium-filled flowable restorative material as pit and fissure sealant. Oper Dent 2002;27(4):325-329. https://pubmed.ncbi.nlm.nih.gov/12120768/

13. Duangthip $D$, Lussi $A$. Variables contributing to the quality of fissure sealants used by general dental practitioners. Oper Dent 2003;28(6):756-764. https://pubmed.ncbi.nlm.nih.gov/14653291/

14. do Rego MA, de Araujo MAM. Microleakage evaluation of pit and fissure sealants done with different procedures, materials, and laser after invasive technique. J Clin Pediatr Dent 1999;24(1):63-68. Available from: https://pubmed.ncbi.nlm.nih.gov/10709546/

15. Francescut $P$, Lussi $A$. Performance of a conventional sealant and a flowable composite on minimally invasive prepared fissures. Oper Dent 2006;31(5):543-550. DOI: 10.2341/05-91.

16. Muller-Bolla M, Lupi-Pégurier $L$, Tardieu $C$, et al. Retention of resinbased pit and fissure sealants: a systematic review. Community Dent Oral Epidemiol 2006;34(5):321-336. DOI: 10.1111/j.16000528.2006.00319.x.

17. Garcia RN, Morelli AE, da Silva BS, et al. Bonding performance of a selfadhering flowable composite to substrates used in direct technique. RSBO 2013;10(4):343-349. Available from: http://revodonto.bvsalud. org/scielo.php?script=sci_arttext\&pid=S1984-56852013000400007 